\title{
Commentary
}

\section{Discrimination of Young Workers: To be Justified or not to be Justified?}

\author{
By Beryl ter Haar, Assistant Professor European and International Labour \\ Law and Academic Coordinator Adv. LL.M. Global and European Labour \\ Law, Leiden University, The Netherlands
}

\section{Introduction}

In the case Abercrombie the Court of Justice of the European Union (CJEU) had to decide on a measure of the Italian government which allows for an unrestricted use of on-call contracts for workers up till the age of 25 or over the age of 45 (amended to 55). Antonino Bordonaro was employed by Abercrombie \& Fitch on such a contract. When he reached the age of 25 the employment contract was terminated ex lege. Bordonaro raised a claim that the measure is discriminatory since the only criterium for termination is age. The CJEU concluded that the measure constitutes discrimination on the grounds of age now that age is the sole criterium for the termination of the on-call contract. Therefore, based on Art. 6 of Directive 2000/78, the CJEU had to consider whether the discriminatory measure can be objectively justified by a legitimate aim and whether the measure is necessary and proportionate to achieve that aim. The CJEU came to the somewhat surprising conclusion that the measure can be objectively justified, despite the reservations on this made by Advocate General Bobek who suggested that the distinction based solely on age was not necessary, since it could also be based on other criteria that would not be discriminatory. 


\section{The Judgement}

To justify the measure the Italian government put forward three underlying goals for the measure that are interrelated, yet not overlapping. First the measure is "part of a legal framework aiming at promoting flexibility in the job market, in order to increase the employment rate"; second the measure aims to foster "the entry of young people in the labour market"; and third, more specifically, the measure aims "to provide for the first opportunity to be employed, thus allowing for initial and subsequent relevant experience on the job market, but not for stable employment". Advocate General Bobek of the CJEU indicates that in itself each of these goals could constitute a legitimate aim, the problem though is to establish the appropriateness, consistency and necessity of the measure. ${ }^{2}$ Assessing each of the underlying aims for their appropriateness, consistency and necessity, AG Bobek indicates doubts for each of the aims. With respect to the first aim AG Bobek raises the question why the burden to achieve flexibility in the labour market should be borne by certain age groups only. ${ }^{3}$ Regarding the second aim AG Bobek refers to the Commissions argument that the measure is likely to shift the problem of unemployment to another, the next, age group, those older than 25 whose employment relationship based on the on-call contract has automatically been terminated. In other words, the aim of the measure is not consistent enough and therefore the national court should examine a less intrusive alternative for automatic dismissal. ${ }^{4}$ With regard to the third aim AG Bobek finds another inconsistency, namely that persons who start to work at a younger age may enjoy the benefits of gaining job experience for several years whereas those closer to 25 would enjoy it only for a short period. This results into inequality within the same age group, namely those younger than $25 .{ }^{5}$ Overall, AG Bobek casts doubts about the clarity and coherence of the aims of the measure, which assessment is encapsulated in the test for the necessity and appropriateness of the measure. ${ }^{6}$

Unlike AG Bobek, the CJEU does not read the underlying aims of the measure separately, instead it interprets them interrelated as the Italian government has presented it during the hearing. Thus, the reading of the CJEU regarding the objective justification to legitimize the discriminatory rule is as follows.

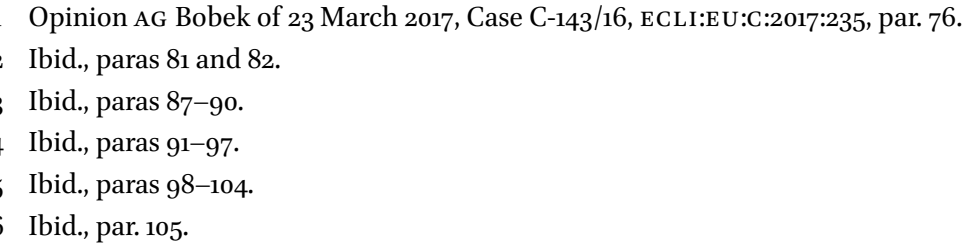


The measure to allow unrestricted use of on-call contracts for workers up till the age of 25 very possibly facilitates the entry of young people to the labour market. Something that is important in a labour market as difficult as the Italian one in which the lack of professional experience is a factor that hampers young people's access to the labour market. Moreover, "the possibility of entering the world of work and of acquiring experience, even if it is flexible and limited in time, could constitute a springboard towards new employment opportunities." ${ }^{7}$ The CJEU therefore concludes that the measure falls within the second subparagraph of Art. 6(1) Directive 2000/78 including justified differences in treatment of conditions on access to employment, as well as conditions for dismissal when such a measure promotes the vocational integration of, among others, young people, or when it ensures their protection. ${ }^{8}$

The CJEU further supports its conclusion with reference to the cases Fuchs and Köhler (the promotion of access of young people to a profession could constitute a legitimate aim), ${ }^{9}$ De Lange (legitimate for the purposes of Art. 6(1) Directive $2000 / 78$ is a tax measure that is more favourable for young workers up till the age of 30 in order to promote their position on the labour market in order to promote their vocational integration or to ensure their protection), ${ }^{10}$ and Kücükdeveci (facilitation of recruitment of younger workers by increasing the flexibility of personnel management constitutes a legitimate aim). ${ }^{11}$

Having established that the measure in the main procedure serves a legitimate aim that falls within the scope of Art. 6(1) Directive 2000/78, the CJEU continues with the assessment of the appropriateness and necessity of the measure. With respect to the appropriateness of the measure the CJEU concludes that the measure is appropriate, since the view may be taken that "undertakings may be encouraged by the existence of an instrument less onerous and costly than the usual contract and thus be prompted to respond more to job applications from young workers." ${ }^{12}$ Furthermore, the CJEU considered the measure appropriate since it is accompanied by a number of guarantees. Hence, the CJEU considers the measure to pursue a legitimate aim of social

\footnotetext{
7 CJEU of 19 July 2017, case C-143/16, ECLI:EU:C:2017:566, par. 33.

8 Ibid., par. 36 .

9 Ibid., par. 37; and CJEU of 21 July 2011, joint cases C-159/10 and C-16o/10, ECLI:EU:C:2011:508, par. 49 .

10 Ibid., par. 38; and CJEU of 10 November 2016, case C-548/15, ECLI: EU:C:2016:850, par. 27.

11 Ibid., par. 38, and CJEU of 19 January 2010, case C-555/07, ECLI: EU:C:2010:21, paras. 35 and 36 .

12 Ibid., par. 41.
} 
and employment policy which is capable to achieve that aim and in that light finds the measure necessary and appropriate.

\section{Analysis of the Judgement}

Compared to previous cases dealing with age discrimination affecting young people this decision is remarkable. So far, the CJEU has been rather strict in the assessment of the necessity and appropriateness of measures affecting young people. ${ }^{13}$ In particular it is in contrast and rather unexpected in comparison with the case Hütter. In Hütter the CJEU had to assess an Austrian provision of the Law on Contractual Public Servants, which states that only persons above the age of fifteen can be recruited as public servants and excludes periods of service completed before the age of eighteen from entitlements related to the length of service or professional experience. The aim of the measure was twofold: first, it encourages pupils to pursue a general secondary education rather than vocational education; and second, it seeks to promote the recruitment of persons who have had a vocational education rather than of persons with a general secondary education. While the CJEU concluded that these aims are inconsistent, even contradictory - it aims to promote general secondary education over vocational training, but then seems to favour vocational training over general secondary education - it nonetheless accepted it as legitimate aims within the context of Art. 6 of Directive 2000/78. However, it is because of this inconsistency the CJEU concluded that the measure cannot be necessary or appropriate. It is needless to say that a measure which is contradictory cannot achieve its aim. Additionally, the CJEU considered that linking the accreditation of experience to age results in unequal award of experience among people of the same age group.

Reading the analysis of AG Bobek in the case Abercrombie it seemed likely that the CJEU would reach a similar conclusion as it did in Hütter, namely because the aims justifying the measure are non-coherent and inconsistent the measure cannot be necessary or appropriate. Also, the link of the termination ex lege of the employment contract with age results in unequal opportunities of gaining work experience among people within the same age group. In Hütter the CJEU rejected the Austrian measure as inappropriate for this reason. In Abercrombie though the CJEU did not.

13 See for an elaborate analyses of these cases: B.P. ter Haar, 'EU Age Discrimination Law: A Curse or a Blessing for EU Youth Policy?', in U. Belavusau \& K. Henrard (eds.) EU AntiDiscrimination Law beyond Gender (Hart Publishing, 2018). 


\section{Consequence for the Practice: to be Justified or not to be Justified?}

What differs in the two situations is the financial-economic situation of the Member States: Austria, at the time of the case in 2006-2007 just before the crisis, prospering rather well with no significant problems regarding youth unemployment; and Italy, at the time of the case in 2014-2016 still in the process of recovering from the crisis and struggling with extremely high numbers of youth unemployment. It seems therefore, that the CJEU is sensitive for a Member State's claim on the necessity of a discriminatory measure because of the extremely difficult socio-economic position of young people at the labour market. Accepting such as legitimate aim of course goes without debate; it is exactly what is covered by Art. 6 of Directive 2000/78. However, when it comes to the test of necessity and appropriateness this is another issue. Especially in light of the test that the measure should be capable to achieve the legitimate aim. In Abercrombie the Italian government claimed that the lack of work experience was one of the main issues hindering young people to get a job. The issue is therefore that people leaving school should get opportunities to gain work experience. The CJEU is correct in concluding that this could be achieved with a measure as at hand which motivates employers to hire young people. The issue is also that young people should have equal opportunities to gain work experience. With age as determining requirement this will not be achieved. On the contrary, young people leaving school at the age of 18 will have seven years to gain work experience, whereas young people leaving school at the age of 23 will have merely two years to gain work experience. While in Hütter the CJEU concluded that linking age to the accreditation of work experience, the CJEU should also have concluded this in the case Abercrombie. The Italian government didn't have to link the use of on-call contracts to age, it could for example have done such connected to a certain period of time, for example three years, after leaving secondary or tertiary education. For the moment though the message from the CJEU to Member States is that having a harsh labour market is enough to justify discrimination on the grounds of age. 